\title{
Unveiling the uncertainty principle in the QRS complex offset detection on high resolution electrocardiography
}

\author{
Olivassé Nasario-Junior, Paulo Roberto Benchimol-Barbosa, Jurandir Nadal*
}

\begin{abstract}
The accuracy of high resolution electrocardiographic (HRECG) methods for stratifying the risk of malignant ventricular arrhythmia depends on the fidelity of QRS fiducial points detection. This study aims at examining the effect of acquisition and processing variables in HRECG on the variability of QRS complex offset (QRS offset) detection in simulated and biological signals, as well as investigating the factors related to the so called uncertainty principle applied to HRECG. Successive QRS offset locations were calculated in different signals configurations including HRECG data from patients with and without ventricular late potentials and simulated data using linear and exponential functions. The expected error in QRS offset detection was assessed as a function of: i) signal characteristics (Simulated or Biological); ii) Sampling Frequency (SF); iii) Residual Noise Level (RNL); iv) QRS maximum amplitudes. The uncertainty principle was related to HRECG and a given exponential signals, and increasing RNL up to $0.5 \mu \mathrm{V}$. SF and RNL are outstanding factors influencing QRS offset variability. Thus, HRECG related uncertainty principle is a deterministic phenomenon associated with both HRECG signal and mathematical formulation of the terminal decay of the QRS complex to the fusion with the ST segment.
\end{abstract}

Keywords High resolution electrocardiogram, Variability of QRS complex offset, Uncertainty principle.

\section{Desvendando o princípio da incerteza na detecção do final do complexo QRS na eletrocardiografia de alta resolução}

Resumo A precisão dos resultados dos exames de eletrocardiografia de alta resolução (ECGAR) para estratificação do desenvolvimento de arritmias ventriculares malignas depende da fidelidade na detecção dos pontos fiduciais do complexo QRS. O presente estudo tem o objetivo de avaliar o efeito das variáveis de aquisição e processamento do ECGAR sobre a variabilidade da detecção do ponto final do complexo QRS (QRS-fim) em sinais biológicos simulados e reais, bem como investigar o efeito de condições relacionadas ao assim formulado "princípio da incerteza da eletrocardiografia de alta resolução". Detecções sucessivas do QRS-fim foram realizadas usando diferentes configurações de sinais simulados e de pacientes com e sem potenciais tardios ventriculares. Os sinais simulados empregaram funções lineares e exponenciais para mimetização da porção final do complexo QRS. O erro de detecção do QRS-fim esperado foi avaliado em função de: i) procedência dos sinais (simulado ou biológico); ii) frequência de amostragem (FA); iii) nível de ruido residual (NRR); iv) amplitude máxima do complexo QRS. A presença do princípio da incerteza relacionou-se ao padrão de decaimento exponencial e ao aumento progressivo da NRR, até 0,5 $\mu V$. FA e NRR têm impacto significativo na variabilidade do QRS-fim. Assim, o principio da incerteza da ECGAR é um fenômeno determinístico dependente da forma de onda relativa ao decaimento da região terminal do complexo QRS até a sua fusão com o segmento ST.

Palavras-chave Eletrocardiograma de alta resolução, Variabilidade do ponto final do complexo QRS, Principio da incerteza. 


\section{Introduction}

The signal-averaged or high resolution electrocardiography (HRECG) is a non-invasive diagnostic tool employed to stratify individuals at risk for developing life threatening ventricular arrhythmias secondary to reentry mechanism, and accurate results have important clinical implications (Ikeda et al., 2007; Marcus et al., 2007). Its purpose is to identify the presence of ventricular late potentials (VLP) at the terminal region of the QRS complex and in the beginning of the ST segment, which are signals originated from abnormal ventricular activation over the damaged myocardium (Simson, 1981). Following the initial scientific interest generated by the method, expectations diminished over time due to significant variability in its predictive accuracy among different studies. However, during the past few years, its predictive value has been re-evaluated either alone or in conjunction with other stratification methods in several cardiac abnormalities (Lacroix et al., 1991; Madias, 2005; Grell et al., 2006; Benchimol-Barbosa, 2007; Ribeiro et al., 2008; Schoenenberger et al., 2008; Liew, 2010; Huebner et al., 2010; Marcus et al., 2010).

Currently, in HRECG, the standard assessment of the signal is based on time domain analysis (Simson, 1981; Breithard et al., 1991), and the success of the diagnostic evaluation depends on the correct signal alignment and identification of both onset and offset points of the QRS complex (Speranza et al., 1996). On the other hand, the morphology and the location of VLPs, as well as the parameters employed in signal acquisition and processing, even when standardized (Breithard et al., 1991), influence the precision and the accuracy of QRS complex end points (QRS offset) estimation. A residual variability in QRS duration in successively performed exams is, thus, observed in the same patient (Goldberger et al., 2000). Notwithstanding, the duration of the QRS complex is the most important index for the risk stratification of ventricular arrhythmia (Uijen et al., 1979; Korhonen et al., 2006; Marcus et al., 2010).

By averaging successive beats, it is possible to reduce the interference or noise whereas relevant signal waveforms are preserved, allowing the identification of VLPs (Benchimol-Barbosa, 2003; Laciar et al., 2003). It is noteworthy that detection algorithms of fiducial points in current practice are based on a threshold level detector, which is calculated from the signalaveraged residual noise level (RNL) (Jane et al., 1991; Breithard et al., 1991).

Two main theories explain the relationship between the RNL and the variability in the detection of the
QRS offset, or the expected detection error $\left(\varepsilon_{\text {expected }}\right)$, in a threshold level detector system. The classic theory, proposed by Uijen et al. (1979) establishes that the variability of any point along the QRS complex, identified by a threshold detector level, will be directly proportional to RNL and inversely proportional to the first derivative at the detection point. On its turn, the uncertainty principle applied to HRECG (Goldberger et al., 2000) states that the lower RNL, the higher the variability (uncertainty) in the estimated QRS offset in successive independently processed HRECG signals.

Several studies have been carried out to investigate the effect of the RNL on the variability of measured indexes and/or the presence of VLP clinically relevant (Steinberg et al., 1989; Sager et al., 1991; Christiansen et al., 1996; Goldberger et al., 2000; Bragge et al., 2005; Frances, 2010). However, those studies are scarce in examining the relationship among acquisition protocol, signal-processing parameters and fiducial point variability in computationally simulated and human biological signals. Thus, the objective of the present study was twofold: i) to investigate the influence of signal acquisition and processing parameters of HRECG in the variability of the QRS offset in simulated and biological signals, and ii) to identify factors related to the uncertainty principle applied to HRECG.

\section{Theoretical modeling of the uncertainty principle}

\section{Detection error theory}

According to Uijen et al. (1979), in a threshold detector, the standard deviation (Detection Error) at a detection point $t=t_{0}$ of a signal, in successive repetitions will be defined as follows.

Considering an ECG signal, defined as function $s(t)$ immerse in ergodic additive noise $r(t)$, with normal distribution of zero average and $\sigma_{r}^{2}$ variance, the output signal, $y(t)$, with a high $S N R$, can be written according to:

$y(t)=s(t)+r(t)$

A threshold level detector at a threshold $\lambda$ will be employed for $y(t)$ detection. At a given time $t_{\lambda}$, $\lambda$ crosses the QRS complex. Thus, it can be written that for a real QRS complex signal:

$\lambda=s\left(t_{\lambda}\right)+r\left(t_{\lambda}\right)$

where, $t_{\lambda}$ represents the time at which the threshold level $\lambda$ crosses the QRS complex. 
Because of the noise, the instant $t_{\lambda}$ will be a random variable, with average $\mu\left(t_{\lambda}\right)$ and variance $\sigma^{2}\left(t_{\lambda}\right)$, and the threshold $\lambda$ level can be re-written to consider the two first terms of the Taylor series expansion:

$$
\begin{aligned}
\lambda \cong & s\left(\mu\left(t_{\lambda}\right)\right)+r\left(\mu\left(t_{\lambda}\right)\right)+ \\
& \left(t_{\lambda}-\mu\left(t_{\lambda}\right)\right) \cdot\left[s^{\prime}\left(\mu\left(t_{\lambda}\right)\right)+r^{\prime}\left(\mu\left(t_{\lambda}\right)\right)\right]
\end{aligned}
$$

where $s^{\prime}\left(\mu\left(t_{\lambda}\right)\right)$ and $r^{\prime}\left(\mu\left(t_{\lambda}\right)\right)$ represent the first derivate of $s(t)$ and $r(t)$, respectively, at time $\mu\left(t_{\lambda}\right)$.

Furthermore, in an ideal case, detection point at threshold level $\lambda=s\left(\mu\left(t_{\lambda}\right)\right)$. By replacing $\lambda=s\left(\mu\left(t_{\lambda}\right)\right)$ in the Equation 3 and making appropriate arrangements, $\lambda$ is dropped from both sides of the equation, which changes into:

$$
t_{\lambda} \cong \mu\left(t_{\lambda}\right)-\frac{r\left(\mu\left(t_{\lambda}\right)\right)}{s^{\prime}\left(\mu\left(t_{\lambda}\right)\right)+r^{\prime}\left(\mu\left(t_{\lambda}\right)\right)}
$$

if $S N R$ is high, $r^{\prime}\left(\mu\left(t_{\lambda}\right)\right)$ in the denominator can be dropped in relation to $s^{\prime}\left(\mu\left(t_{\lambda}\right)\right)$, what simplifies Equation 4 in:

$t_{\lambda} \cong \mu\left(t_{\lambda}\right)-\frac{r\left(\mu\left(t_{\lambda}\right)\right)}{s^{\prime}\left(\mu\left(t_{\lambda}\right)\right)}$

where $s^{\prime}\left(\mu\left(t_{\lambda}\right)\right)$ is constant, $r\left(\mu\left(t_{\lambda}\right)\right)$ is the noise value and $\mu\left(t_{\lambda}\right)$ is average detection time, $t_{\lambda}$. Now, obtaining the variance of variable $t_{\lambda}, \sigma^{2}\left(t_{\lambda}\right)$ in Equation 5, the result will be:

$$
\sigma^{2}\left(t_{\lambda}\right) \cong \frac{\sigma_{r}^{2}}{s^{\prime 2}\left(\mu\left(t_{\lambda}\right)\right)}
$$

Thus, Equation 6 demonstrates that the variance of the detection point, $\sigma^{2}\left(t_{\lambda}\right)$, will be directly proportional to the baseline residual noise variance, $\sigma_{r}^{2}$.

Now, consider $f(t)$ as a function that represents the QRS complex decay at the terminal region. In classical QRS end point detectors, the threshold level, $\lambda$, is defined as multiple of the SD of the baseline noise (Breithard et al., 1991). By arbitrarily taking the detection threshold $\lambda$ as three times the SD of the signal baseline noise $(\lambda=3 . S D)$, the threshold at the QRS offset $\left(t_{\mathrm{o}}\right)$ will then correspond to $f\left(t_{\mathrm{o}}\right)$. Defining the detection error at $t_{\mathrm{o}}\left(\varepsilon_{\mathrm{o}}\right)$ as the SD at $t_{\mathrm{o}}$ in successive independent detections procedures, which corresponds to the square root of $\sigma^{2}\left(t_{\lambda}\right)$ in Equation 6, that is $\varepsilon_{\mathrm{o}}=\sigma\left(t_{\lambda}\right)$, the behaviors of $\varepsilon_{\mathrm{o}}$ is analyzed below in three particular cases of $f(t)$.

\section{Linear case theory}

At the QRS complex offset point, where $f\left(t_{\mathrm{o}}\right)=\lambda$,

$$
\begin{aligned}
& f(t)=\frac{A(N-t)}{N} \rightarrow \frac{d f(t)}{d t}=-\frac{A}{N} \\
& \rightarrow \text { because } t_{0}=1-N \cdot\left[\frac{f\left(t_{0}\right)}{2}-1\right], \text { then: }
\end{aligned}
$$

$\varepsilon_{o}=\frac{f\left(t_{o}\right)}{\frac{d f\left(t_{o}\right)}{d t}}=N \cdot \frac{\lambda}{A}$

where $A$ is the QRS complex maximum amplitude; $N$ is QRS duration; $t_{\mathrm{o}}$ is time corresponding to the intersection of QRS complex end points by the threshold detector; $f\left(t_{\mathrm{o}}\right)$ is a function corresponding to the QRS complex end points at the threshold detection $\left(\lambda=f\left(t_{\mathrm{o}}\right)\right)$; and $\varepsilon_{\mathrm{o}}$ is the detection error. Therefore, in this case $\varepsilon_{\mathrm{o}}$ will be linear and directly related to the baseline noise level $(\lambda=3 . S D)$, thus rejecting in Equation 7 the uncertainty principle postulation.

\section{Exponential case theory}

A general form of the exponential function $f(t)=A e^{-\frac{k t^{p}}{p}}$ was employed to simulate QRS complex offset, modified from Bragge et al. (2005). By taking at threshold level, $f\left(t_{\mathrm{o}}\right)=\lambda$, it follows

$$
\begin{aligned}
& f(t)=A e^{-\frac{k t^{p}}{p}} \rightarrow \frac{d f(t)}{d t}=-A k t^{p-1} e^{-\frac{k t^{p}}{p}} \\
& \rightarrow \text { because } t_{o}=\sqrt[p]{\frac{p}{k} \cdot \ln \left(\frac{A}{f\left(t_{o}\right)}\right)}, \text { then: } \\
& \varepsilon_{o}=\frac{f\left(t_{o}\right)}{\frac{d f\left(t_{o}\right)}{d t}}=\frac{\left[\frac{p}{k} \cdot \ln \left(\frac{A}{\lambda}\right)\right]^{1 / p}}{p \cdot \ln \left(\frac{A}{\lambda}\right)}
\end{aligned}
$$

where $k$ is a decay constant.

Exponential Case $\mathrm{p}>1,[\mathrm{p}=2$, in Equation 8]At the QRS complex offset point, where $\mathrm{f}\left(\mathrm{t}_{\mathrm{o}}\right)=\lambda$,

$f(t)=A e^{-\frac{k t^{2}}{2}} \rightarrow \frac{d f(t)}{d t}=-A k t e^{-\frac{k t^{2}}{2}}$

$\rightarrow$ because $t_{o}=\sqrt[p]{\frac{2}{k} \cdot \ln \left(\frac{A}{f\left(t_{o}\right)}\right)}$, then:

$\varepsilon_{o}=\frac{f\left(t_{o}\right)}{\frac{d f\left(t_{o}\right)}{d t}}=\frac{1}{\sqrt{2 \cdot k \cdot \ln \left(\frac{A}{\lambda}\right)}}$

similar to the observed in the linear case, fixed both signal amplitude $(A)$ and constant decay $(\mathrm{k}), \varepsilon_{\mathrm{o}}$ will be directly related to the baseline noise level (expressed as a function of the baseline noise level, $\lambda=3 \cdot S D$ ), thus, rejecting the uncertainty principle in Equation 9.

Exponential Case $[p=1$, in Equation 8]-At the QRS complex offset point, where $\mathrm{f}\left(\mathrm{t}_{\mathrm{o}}\right)=\lambda$,

$$
\begin{aligned}
& f(t)=A e^{-k t} \rightarrow \frac{d f(t)}{d t}=-A k e^{-k t} \\
& \rightarrow \text { because } t_{o}=\frac{1}{k} \cdot \ln \left(\frac{A}{f\left(t_{o}\right)}\right), \text { then: } \\
& \varepsilon_{o}=\frac{f\left(t_{o}\right)}{\frac{d f\left(t_{o}\right)}{d t}}=\frac{1}{k}
\end{aligned}
$$


similar to the observed in the linear case, fixed both signal amplitude $(A)$ and constant decay $(\mathrm{k}), \varepsilon_{\mathrm{o}}$ will be invariant for any baseline noise level, thus, rejecting the uncertainty principle in Equation 10.

Exponential Case $0<\mathrm{p}<1$, [p $=0.5$, in Equation 8] - At the QRS complex offset point, where $\mathrm{f}\left(\mathrm{t}_{\mathrm{o}}\right)=\lambda$,

$f(t)=A e^{-\frac{k t^{0.5}}{0.5}} \rightarrow \frac{d f(t)}{d t}=-A k t^{-0.5} e^{-\frac{k t^{0.5}}{0.5}}$

$\rightarrow$ because $t_{o}=\left[\frac{0.5}{k} \cdot \ln \left(\frac{A}{f\left(t_{o}\right)}\right)\right]^{2}$, then :

$\varepsilon_{o}=\frac{f\left(t_{o}\right)}{\frac{d f\left(t_{o}\right)}{d t}}=\frac{0.5 \cdot \ln \left(\frac{A}{\lambda}\right)}{k^{2}}$

different from what was observed in $p>1$ and $\mathrm{p}=1$ cases, fixed both signal amplitude (A) and constant decay $(\mathrm{k}), \varepsilon_{\mathrm{o}}$ will be inversely related to the baseline noise level $(\lambda=3 . S D)$, thus demonstrating the uncertainty principle in high resolution electrocardiography in Equation 11.

\section{Methods}

The simulated signals were generated from mathematical functions mimicking the terminal region of ventricular activation waveform, as follows (Figure 1): i) In perfect alignment and constant derivate, by a linear function (LIN), given by

$$
f(i \cdot S F)=\frac{A(N-i)}{N} ; 0 \leq i \leq N
$$

where $A$ is the maximum amplitude, $N$ represents duration from peak R-wave to QRS offset, $i$ a discrete time in this interval, sampled at an appropriate arbitrarily defined sampling frequency, $\mathrm{S} F$; and ii) In non-perfect alignments and variable derivates, by exponential functions (EXP), given by

$$
f(i \cdot S F)=A e^{-0.5 \cdot \frac{i^{p}}{p}}
$$

Exponential functions were analyzed in three particular cases, for $p$ (constant decay) equal to 0.5 $\left(\mathrm{EXP}^{0.5}\right), 1\left(\mathrm{EXP}^{1}\right)$ and $2\left(\mathrm{EXP}^{2}\right)$.

Each simulated QRS complex (linear and exponentials) was additionally implemented with five different maximum amplitudes $A(0.01,0.05,0.1,0.5$ and $1 \mathrm{mV}$ ). For appropriate comparison with human biological signals, such amplitudes were named in electric tension unit $(V)$. Each signal configuration was sampled in different sampling frequencies $(1,2,5$ and $10 \mathrm{kHz})$ and added to different RNLs $(0.2,0.3,0.4,0.5,0.6,0.7$ and $0.8 \mu \mathrm{V})$ that were

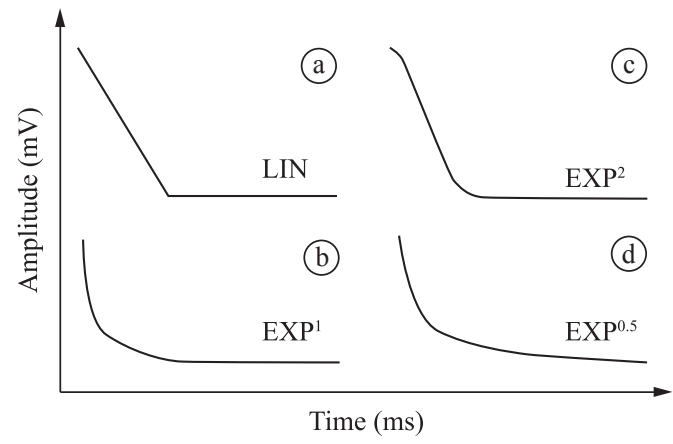

Figure 1. Terminal QRS complex decay function simulation. Examples of signals simulating the terminal region of the activation waveform (QRS complex): a) Linear, b) Exponential $(p=1)$, c) Exponential $(p=2)$, d) Exponential $(p=0.5)$. See text for details.

within the standardized limits for clinical HRECG use (Breithard et al., 1991).

According to the theorem demonstrated by Uijen et al. (1979),

$$
\varepsilon_{\text {expected }}=\frac{R N L}{|\Delta f(i)|}
$$

where $\Delta f(i)$ is the first derivative of $f(i), f(i) \equiv f(i \cdot S F)$ and $\varepsilon_{\text {expected }}(\varepsilon=$ detection error $)$ was calculated according to the respective simulating function property.

The estimated $\varepsilon_{\text {expected }}$ shows, in the linear case, the QRS offset detection variability must exclusively depend on the RNL, considering the constant first derivate. In the exponential cases, estimated $\varepsilon_{\text {expected }}$ depends on RNL, maximum QRS amplitude and constant decay $(p)$, which determines signal derivative at the detection point.

The human biological signals (BIO) were assessed in two different groups adjusted by age, gender and anthropometric indexes. Control group consisted of 18 healthy volunteers' signals, age $52.1 \pm 10.2$ years (mean \pm standard deviation), without documented heart disease and the experiment group (age $58.7 \pm 12.9$ years), comprising 18 subjects with past history of syncope of cardiac origin and documented sustained monomorphic ventricular tachycardia (SMVT Group), either spontaneous or induced in electrophysiology study. Subjects in both groups were in sinusal rhythm, and none presented complete bundle branch block. An informed consent was obtained from all subjects before participation.

The ECG signals were acquired after $10 \mathrm{~min}$ of supine rest. The HRECG signals were acquired using XYZ orthogonal bipolar Frank leads during 20 min, with three-channel electrocardiograph (Lynx Tecnologia, São Paulo, Brazil), with $10 \mathrm{G} \Omega$ input impedance, $-120 \mathrm{~dB} /$ channel common mode rejection, 
and analog band-pass filter from 1 to $300 \mathrm{~Hz}$ (2nd order Butterworth filter). Signals were sampled with a $14 \mathrm{bit} \mathrm{A} / \mathrm{D}$ converter at a sampling frequency of $1 \mathrm{kHz}$ and stored in a personal computer. All patients were in sinus rhythm and resting comfortably in the supine position during acquisition. The skin was cleaned with slight abrasion, and adhered with $\mathrm{Ag} / \mathrm{AgCl}$ electrodes (3M, USA).

Each lead was analyzed to exclude ectopic and excessive noisy beats (a beat rejection automatically eliminated the following beat). Using the X-lead as a reference, the system identified each beat, after a template generated and updated until the $10^{\text {th }}$ consecutive normal accepted beat. To be considered compatible with the template, a given beat has to present a minimum correlation coefficient to 0.8 . Each accepted beat was appropriately synchronized, according to an algorithm modified from Jane et al. (1991), and averaged after weighting with the inverse of the spectral power between $40-250 \mathrm{~Hz}$ and carried out until a noise below $0.2 \mu \mathrm{V}$.

Each lead was, then, bidirectionally filtered (Butterworth $4^{\text {th }}$ order / 40-250 Hz band-pass) and gathered in the vector magnitude $\left(\mathrm{Vm}=\left(\mathrm{X}^{2}+\mathrm{Y}^{2}+\mathrm{Z}^{2}\right)^{1 / 2}\right)$, in which were identified the QRS offsets (Simson, 1981).

In all BIO signals, RNL was set at similar levels implemented in simulated signals for assessing the effect on QRS offset detection. Digital data sampling was also adjusted to 2, 5 and $10 \mathrm{kHz}$, by cubic spline interpolation. All tested signals (Table 1) had the same duration, equal to $512 \mathrm{~ms}$ (Jane et al., 1991).

The maximal amplitudes of simulated signals were arbitrarily defined aiming at analyzing the detection algorithm in extreme situations of minimal $(0.01,0.05$ and $0.1 \mathrm{mV})$ and maximal amplitude $(0.5$ and $1 \mathrm{mV}$ ). Particularly, 0.1 and $0.5 \mathrm{mV}$ amplitude were the ones that approached HRECG signals after processing and bi-directional filtering (maximal amplitude: Control Group: $0.30 \pm 0.08 \mathrm{mV}$ and SMVT Group: $0.31 \pm 0.11 \mathrm{mV}$ ).
The RNL was implemented with a normally-distributed random number generation function. The verification of generated RNL was carried out by variance calculation in a 100 points window width located over the baseline. For each level, noises were statistically compared by the $\chi^{2}$ test $(\alpha=0.05)$.

The QRS offset variability was analyzed in each signal configuration (total configurations $=2576$ ) that combined specific characteristics (Table 1). For each set of configurations, it was generated 5000 simulated signals and 500 biological signals. The algorithms for both simulation and identification of the ventricular activation were implemented in Matlab ${ }^{\circledR}$ version 6.5 software (The MathWorks, Natick, USA).

The QRS offset values were stored in a vector for subsequent mean and standard deviation (SD) calculation. Those parameters were analyzed as a function of RNL in each signal configuration aiming at analyzing the QRS offset variability behavior according to presence of uncertainty principle (i.e., increasing for $\varepsilon_{\text {expected }}$ and decreasing for uncertainty principle).

The uncertainty principle applied to HRECG establishes that the RNL is inversely proportional to the SD of the QRS offset location in a series of independent measures. A reciprocal relationship between QRS offset SD and RNL was arbitrarily defined by a general multiplicative equation:

$$
y=C x^{D}
$$

where, $x$ and $y$ are reciprocal variables and $\mathrm{C}$ and $\mathrm{D}$, appropriate coefficients. To properly estimate the coefficients, a linear transformation (natural logarithm) was carried out according to a minimum squared method. The data adjustment to the multiplicative model was assessed by the Pearson's correlation coefficient (r). The following hypothesis $(\alpha=0.05)$ were formulated to validate the presence of uncertainty principle: i) One-sided Student $t$-test applied to the Pearson's correlation coefficient (r), taking as $\mathrm{H}_{0}$ the absence of correlation ( $\mathrm{r}=0)$, ii) One-sided

Table 1. Number of signal configurations and simulations. $A=$ amplitude (maximum); $S F=$ sampling frequency; $R N L=$ residual noise level;

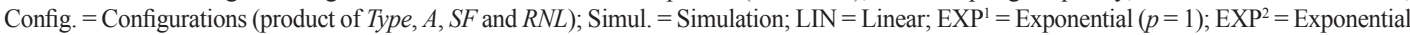
$(p=2) ; \operatorname{EXP}^{0.5}=$ Exponential $(p=0.5) ;$ Control $(18)=18$ subjects of Control group; SMVT $(18)=18$ subjects of SMVT group.

\begin{tabular}{|c|c|c|c|c|c|}
\hline Type & $A(\mathrm{mV})$ & $S F(\mathbf{k H z})$ & $R N L(\mu V)$ & Config. & Simul. \\
\hline LIN (1) & 5 & 4 & 7 & 140 & 5000 \\
\hline $\mathrm{EXP}^{1}(1)$ & 5 & 4 & 7 & 140 & 5000 \\
\hline $\mathrm{EXP}^{2}(1)$ & 5 & 4 & 7 & 140 & 5000 \\
\hline $\operatorname{EXP}^{0.5}(1)$ & 5 & 4 & 7 & 140 & 5000 \\
\hline Control (18) & 1 & 4 & 7 & 504 & 500 \\
\hline SMVT (18) & 1 & 4 & 7 & 504 & 500 \\
\hline Total & & & & 1568 & 3304000 \\
\hline
\end{tabular}


Student $t$-test applied to mean angular coefficient (D), taking as $\mathrm{H}_{0}$ if $\mathrm{D}$ was null or positive ( $\mathrm{D} \geq 0$ ). Angular coefficient was hypothesized to show normal distribution. Adjustment tests were carried out only in data sets where the null hypothesis was rejected in test (i) and rejected in test (ii), indicating the occurrence of uncertainty principle. In those data sets where tests (i) and (ii) showed different results association, uncertainty principle was rejected.

In order to test the homocedasticity among RNL classes, the respective variances (SD squared) were compared by Cochran's test $(\alpha<0.05)$. In case of rejected $\mathrm{H}_{0}$ a post-hoc Snedecor's F-test was employed $(\alpha<0.05)$ in the two-by-two comparison to identify those statistically different.

The SD values for each set of simulated signals were grouped according to the RNL (mean SD values of all amplitudes $[\mathrm{mV}]$ and sampling frequencies $[\mathrm{kHz}]$ ) and referred as calculated detection error $\left(\varepsilon_{\text {calculated }}\right)$.

The numeric results are presented as: Mean \pm Standard Error of the Mean (SEM).

\section{Results}

The mean value of $\varepsilon_{\text {calculated }}$ (for all sampling frequency) by RNL and respective SEM in different configurations (Table 1), as well as the respective $\varepsilon_{\text {expected }}$ values are presented in the Figure 2 for simulated signals. The statistics tests validate the presence of uncertainty principle for $\mathrm{EXP}^{0.5}$ and, the respectives $p$ values $(*<0.05 ; \#<0.0001)$ identified those statistically different from the smallest $\varepsilon_{\text {calculated }}$ value.

For biological signals, similar analyses were grouped according to RNL for all SF; i) for each group (Control and SMVT), ii) including both groups of biologic signals (Figure 3).

The $\varepsilon_{\text {calculated }}$ for biologic signals were compared according to the sampling frequency and RNL (Figure 4), with the lower variability region (arrow) of the QRS offset detection for biologic is around the noise $0.5 \mu \mathrm{V}$ and sampling frequency of $10 \mathrm{kHz}$. Note that the uncertainty principle hypothesis was rejected for the $1 \mathrm{kHz}$ sequence.

\section{Discussion}

The uncertainty principle applied to HRECG establishes a reciprocal relationship between RNL and the QRS offset variability. Thus, the lower the RNL the higher will be QRS offset $\varepsilon_{\text {calculated }}$ in successive independent repetitions of the detection process, and vice-versa.

For the simulated signals, all estimated errors were similar to those calculated (Figure 2), and the outline characteristic for uncertainty principle

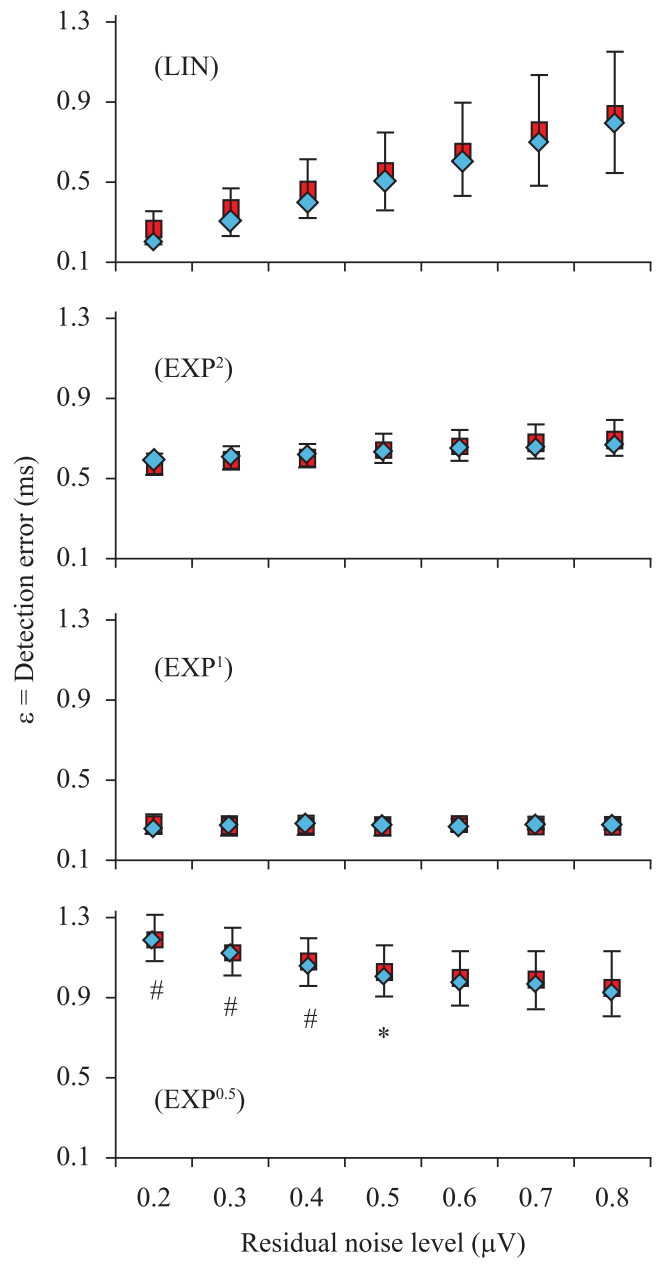

Figure 2. Detection error analysis in simulated signals. Detection Error $(\varepsilon)$ values of simulated signal by residual noise level $(\varepsilon$; mean \pm SEM of all sampling frequencies): $(\diamond) \varepsilon_{\text {expected }},(\square) \varepsilon_{\text {calculated }}(\perp)$ $\mathrm{SEM}=$ standard error of the mean. $\mathrm{LIN}=$ Linear; $\mathrm{EXP}^{1}=$ Exponential $(p=1) ; \operatorname{EXP}^{2}=\operatorname{Exponential}(p=2) ; \operatorname{EXP}^{0.5}=\operatorname{Exponential}(p=0.5)$. $(*=p<0.05 ; \#=p<0.0001)$. See text for details.

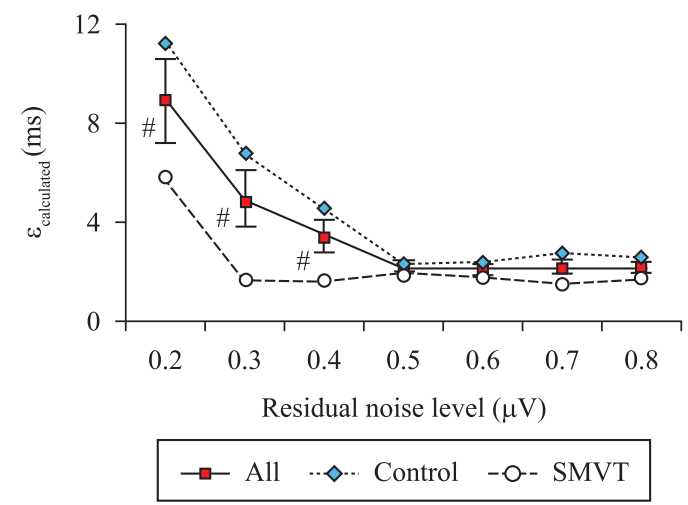

Figure 3. Detection error analysis in human biological signals. $\varepsilon_{\text {calculated }}$ values of human biological signal by residual noise level ( $\varepsilon$; mean \pm SEM of all sampling frequencies): $(\diamond)$ Control group $\varepsilon_{\text {calculated }}$ (O) SMVT group $\varepsilon_{\text {calculated }}(\square) \varepsilon_{\text {calculated }}$ of all groups, $(\perp)$ SEM $=$ standard error of the mean. $(\#=p<0.0001)$. See text for details. 


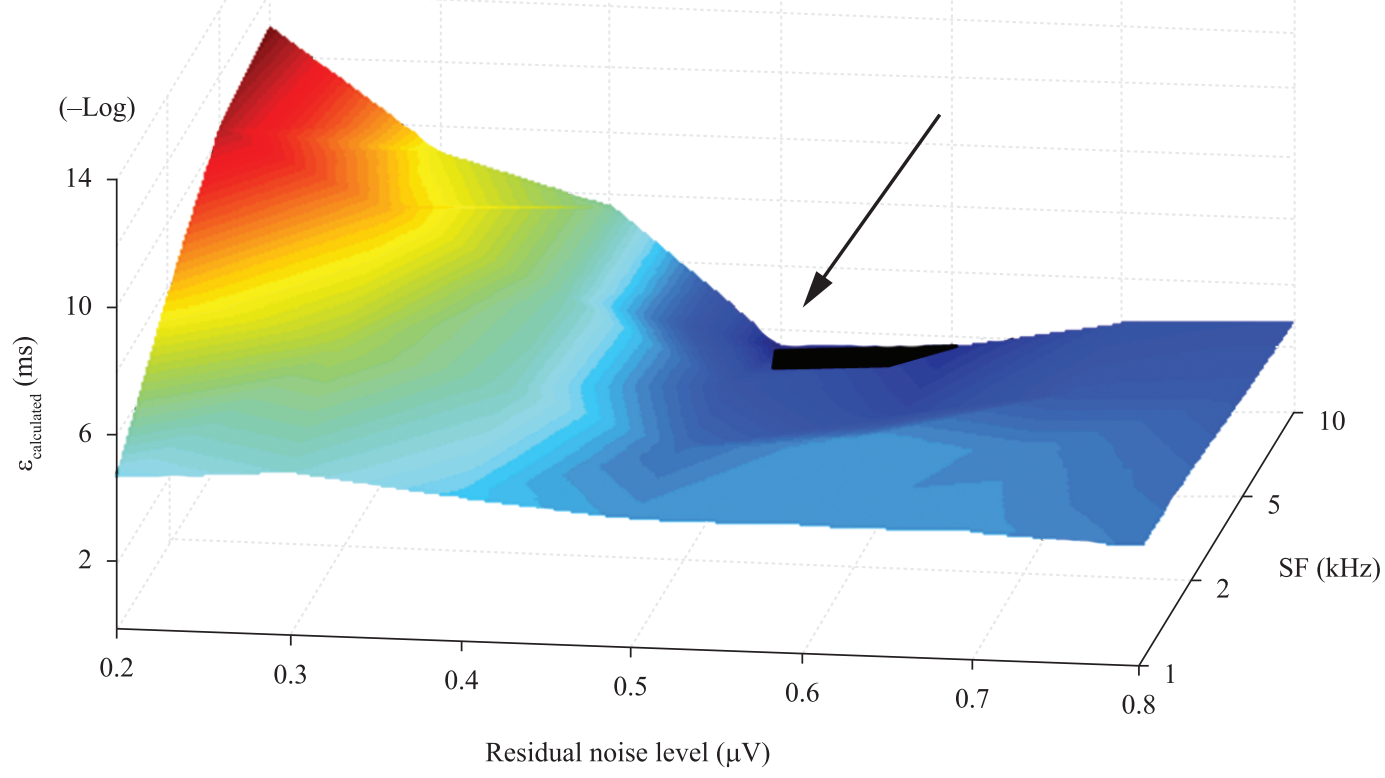

Figure 4. Waterfall for detection error in human biological signals. The calculated detection error $\left(\varepsilon_{\text {calculated }}\right)$ of all human biological signals by sampling frequency (SF) and residual noise level (RNL). Arrow indicates lowest $\varepsilon_{\text {calculated }}$ See text for details.

presence was observed only in the exponential case where $p=0.5\left(\mathrm{EXP}^{0.5}\right)$. These findings indicate that the uncertainty principle was actually consistent with a deterministic characteristic of the signal, particularly in HRECG. Conversely, the uncertainty principle as mathematically determined points to a particular decay pattern of the terminal region of the QRS complex in real conditions, which was better represented by an exponential function in the present study (case $p=0.5$ ).

It is particularly noteworthy that the theorem as proposed by Uijen et al. (1979) was capable to satisfactorily predict the QRS offset to RNL variability in all of the simulated signals.

Uncertainty principle was associated to biologic and simulated signals with well-defined mathematic characteristics (case $p=0.5$ ). In biologic signals, its presence was characterized by lower RNL $(0.2-0.5 \mu \mathrm{V})$ and a high sampling frequency (Figure 4). On the other hand, in biologic signals with VLP (SMVT group) $\varepsilon_{\text {calculated }}$ to RNL relationship deviated from the multiplicative relationship defining uncertainty principle (Figure 3). In this setting, the QRS offset variability was roughly unchanged from $0.8 \mu \mathrm{V}$ to $0.3 \mu \mathrm{V}$ and then increased at the lowest analyzed $\operatorname{RNL}(0.2 \mu \mathrm{V})$.
For biological signals, the configuration that obtained the lower QRS offset variability was the one that combined RNL of $0.5 \mu \mathrm{V}$ and SF of $10 \mathrm{kHz}$ (Figure 4). Additionally, the uncertainty principle regression line was statistically significant only for sampling frequency above $1 \mathrm{kHz}$. The angular coefficient values (D) tend to decrease for sampling frequencies above $2 \mathrm{kHz}$, suggesting that the uncertainty principle could be defined for increased time resolution, exclusively for this signal configuration. However, the statistical tests (Figure 3) show a decreasing behavior on $\varepsilon_{\text {calculated }}$ values (for all groups) only for the lower values of RNL $(0.2-0.5 \mu \mathrm{V})$. It indicates that a progressive decrease in HRECG RNL values causes an increased exposition of lower amplitude HRECG regions, with lower first derivative values that characterizes the limits of QRS offset. On the other hand, a higher RNL (0.6-0.8 $\mu \mathrm{V})$ determined QRS offset stability, further shortening the QRS duration and excluding regions of low signal amplitude. They were, therefore, inappropriate for VLPs detection. Then, higher sampling frequencies associated with intermediate RNL determined the lowest detection error levels, being, therefore, recommended for acquisition and processing of these signals.

Some limitations need to be addressed. First, sampling frequency was computationally increased 
in order to test its contribution in QRS offset detection. Golden et al. (1973) demonstrated that by increasing sampling frequency it would not cause additional information to be detected. Second, QRS offset was simulated by mathematical functions (Bragge et al., 2005), which are approximations of real world waveforms.

\section{Conclusion}

The simulated signals based on linear and exponential functions (excepting the case where $p=0.5$ ), with different peak values and SFs, did not show the behavior that is expected by the uncertainty principle, following the theorem proposed by Uijen et al. (1979), since the QRS offset variability showed to be influenced by RNL and the first derivative of such offset.

High sampling frequencies $(10 \mathrm{kHz})$ and $\mathrm{RNL}$ around $0.5 \mu \mathrm{V}$ allows optimal late potential identification, obtaining the lowest QRS complex offset point detection variability.

The uncertainty principle of the HRECG signals depends on a particular waveform characteristic at QRS complex offset, which is simulated by a specific exponential decay (case $p=0.5$ ). Thus, it follows a deterministic behavior. The application of these principles may optimize the analysis and the processing of the HRECG signals in the future.

\section{Acknowledgements}

This work was partially supported by Fundação Carlos Chagas Filho de Amparo à Pesquisa do Estado do Rio de Janeiro (FAPERJ) and Brazilian Research Council (CNPq/MCT).

\section{References}

Benchimol-Barbosa PR, Barbosa-Filho J, De Sá CA, Barbosa EC, Nadal J. Reduction of electromyographic noise in the signal-averaged electrocardiogram by spectral decomposition. IEEE Transactions on Biomedical Engineering. 2003; 50(1):114-7. http://dx.doi.org/10.1109/ TBME.2002.807317

Benchimol-Barbosa PR. Noninvasive prognostic markers for cardiac death and ventricular arrhythmia in long-term followup of subjects with chronic Chagas' disease. Brazilian Journal of Medical and Biological Research. 2007; 40(2):167-78. PMid:17273653. http://dx.doi.org/10.1590/S0100879X2006005000061

Bragge T, Tarvainen M P, Ranta-Aho PO, Karjalainen PA. High-resolution QRS fiducial point corrections in sparsely sampled ECG recordings. Physiological Measurement. 2005; 26(5):743-51. PMid:16088065. http://dx.doi.org/10.1088/0967-3334/26/5/013
Breithard G, Cain ME, El-Sherif E, Flowers N, Howbach V, Janse M, Simson MB, Steinbeck G. Standards for analysis of ventricular late potentials using high resolution or signalaveraged electrocardiography. A statement by a Task Force Committee between the European Society of Cardiology, the American Heart Association and the American College of Cardiology. European Heart Journal. 1991; 12(4):473-80. PMid:2065682.

Christiansen EH, Frost L, Molgaard H, Nielsen TT, Pedersen AK. Effect of residual noise level on reproducibility of the signal-averaged ECG. Journal of Electrocardiology. 1996; 29(3):235-41. http://dx.doi. org/10.1016/S0022-0736(96)80086-0

Frances RJ. Low noise level unmasks late potentials on signal-averaged electrocardiography. Experimental and clinical cardiology. 2010; 15(3):e61-4.

Grell ES, De Paula RS, Tobias NMMO, Moffa PJ, Grupi CJ, Mansur AJ. Time domain analysis of the signal averaged electrocardiogram to detect late potentials in heart failure patients with different etiologies. Arquivos Brasileiros de Cardiologia. 2006; 87(3):241-7. http://dx.doi.org/10.1590/ S0066-782X2006001600003

Golden DPJ, Wolthuis RA, Hoffler GW. A spectral analysis of the normal resting electrocardiogram. IEEE Transactions on Biomedical Engineering. 1973; 20(5):366-72. PMid:4727424. http://dx.doi.org/10.1109/TBME.1973.324231

Goldberger JJ, Challapalli S, Waligora M, Kadish AH, Johnson DA, Ahmed MW, Inbar S. Uncertainty principle of signal-averaged electrocardiography. Circulation Journal. 2000; 101(25):2909-15. PMid:10869262.

Huebner T, Goernig M, Schuepbach M, Sanz E, Pilgram R, Seeck A, Voss A. Electrocardiologic and related methods of non-invasive detection and risk stratification in myocardial ischemia: State of the art and perspectives. German Medical Science. 2010; 8:doc27. PMid:21063467. PMCid:2975259.

Ikeda T, Yusu S, Nakamura K, Yoshino H. Risk stratification for sudden cardiac death. Circulation Journal. 2007; 71(suppl. A):A106-14. PMid:17587733. http://dx.doi.org/10.1253/ circj.71.A106

Jane R, Rix H, Caminal P, Laguna P. Alignment methods for averaging of high-resolution cardiac signals: a comparative study of performance. IEEE Transactions on Biomedical Engineering. 1991; 38(6):571-9. PMid:1879846. http://dx.doi.org/10.1109/10.81582

Korhonen P, Husa T, Tierala I, Väänänen H, Mäkijärvi M, Katila T, Toivonen L. QRS duration in high-resolution methods and standard ECG in risk assessment after first and recurrent myocardial infarctions. Pacing and Clinical Electrophysiology. 2006; 29(8):830-6. PMid:16922998. http://dx.doi.org/10.1111/j.1540-8159.2006.00448.x

Laciar E, Jané R, Brooks DH. Improved alignment method for noisy high-resolution ECG and Holter records using multiscale cross-correlation. IEEE Transactions on Biomedical Engineering. 2003; 50(3):344-53. PMid:12669991. http://dx.doi.org/10.1109/TBME.2003.808821

Lacroix D, Dubuc M, Kus T, Savard P, Shenasa M, Nadeau R. Evaluation of arrhythmic causes of syncope: 
Correlation between Holter monitoring, electrophysiologic testing, and body surface potential mapping. American Heart Journal. 1991; 122(5):1346-54. http://dx.doi. org/10.1016/0002-8703(91)90576-4

Liew R. Prediction of sudden arrhythmic death following acute myocardial infarction. Heart Journal. 2010; 96(14):1086-94. PMid:20610456. http://dx.doi.org/10.1136/hrt.2010.194407

Madias JE. Standard electrocardiographic and signalaveraged electrocardiographic changes in congestive heart failure. Congestive Heart Failure. 2005; 11(5):266-71. PMid:16230869. http://dx.doi.org/10.1111/j.15275299.2005.04484.x

Marcus FI, Zareba W, Sherrill D. Evaluation of the normal values for signal-averaged electrocardiogram. Journal of Cardiovascular Electrophysiology. 2007; 18(2):231-3. PMid:17338774. http://dx.doi.org/10.1111/j.15408167.2006.00685.x

Marcus FI, McKenna WJ, Sherrill D, Basso C, Bauce B, Bluemke DA, Calkins H, Corrado D, Cox MG, Daubert JP, Fontaine G, Gear K, Hauer R, Nava A, Picard MH, Protonotarios N, Saffitz JE, Sanborn DM, Steinberg JS, Tandri H, Thiene G, Towbin JA, Tsatsopoulou A, Wichter T, Zareba W. Diagnosis of arrhythmogenic right ventricular ardiomyopathy/dysplasia: proposed modification of the task force criteria. Circulation Journal. 2010; 121(13):1533-41. PMid:20172911. PMCid:2860804. http://dx.doi.org/10.1161/ CIRCULATIONAHA.108.840827

Ribeiro AL, Cavalvanti PS, Lombardi F, Nunes MDOC, Barros MV, Rocha MO. Prognostic value of signalaveraged electrocardiogram in Chagas disease. Journal of Cardiovascular Electrophysiology. 2008; 19(5):502-9.
PMid:18266670. http://dx.doi.org/10.1111/j.15408167.2007.01088.x

Sager PT, Widerhorn J, Pascual M, Leon C, Rahimtoola SH, Bhandari AK. A prospective evaluation of the immediate reproducibility of the signal-averaged ECG. American Heart Journal. 1991; 6(1):1671-8. http://dx.doi.org/10.1016/00028703(91)90011-6

Schoenenberger AW, Erne P, Ammann S, Gillmann G, Kobza R, Stuck AE. Prediction of arrhythmic events after myocardial infarction based on signal-averaged electrocardiogram and ejection. Pacing and Clinical Electrophysiology. 2008; 31(2):221-8. PMid:18233976. http://dx.doi.org/10.1111/j.1540-8159.2007.00972.x

Simson MB. Use of the signal in the terminal QRS complex to indentify patients with ventricular tachycardia after myocardial infarction. Circulation Journal. 1981; 64(2):235-42. PMid:7249291. http://dx.doi.org/10.1161/01.CIR.64.2.235

Speranza G, Bonato P, Antolini R. Analyzing late ventricular potentials. IEEE Engineering in Medicine and Biology Magazine. 1996; 15(3):88-94. http://dx.doi. org/10.1109/51.499765

Steinberg SJ, Bigger-Junior JT. Importance of the endpoint of noise reduction in analysis of the signalaveraged electrocardiogram. American Journal of Cardiology. 1989; 63(9):556-60. http://dx.doi. org/10.1016/0002-9149(89)90898-9

Uijen GJH, Weerd JPC, Vendrik AJH. Accuracy of QRS detection in relation to the analysis of high-frequency components in the electrocardiogram. Medical \& Biological Engineering \& Computing. 1979; 17(4):492-502. http://dx.doi.org/10.1007/BF02447064

\section{Autores \\ Olivassé Nasario-Junior, Jurandir Nadal \\ Programa de Engenharia Biomédica, COPPE, Universidade Federal do Rio de Janeiro - UFRJ, CP 68510, CEP 21941-972, Rio de Janeiro, RJ, Brasil}

